\title{
Total aortic repair for acute type A dissection: Not every patient; not every surgeon
}

\author{
Maral Ouzounian, MD, PhD, and Tirone E. David, MD
}

\footnotetext{
From the Peter Munk Cardiac Centre, Division of Cardiac Surgery, Department of Surgery, University of Toronto, Toronto, Ontario, Canada.

Disclosures: Authors have nothing to disclose with regard to commercial support.

Received for publication Sept 4, 2018; accepted for publication Sept 4, 2018; available ahead of print Oct 10 , 2018.

Address for reprints: Tirone E. David, MD, 200 Elizabeth St 4N-457, Toronto, Ontario M5G 2C4, Canada (E-mail: tirone.david@uhn.ca).

J Thorac Cardiovasc Surg 2019;157:1-2

$0022-5223 / \$ 36.00$

Copyright (c) 2018 by The American Association for Thoracic Surgery

https://doi.org/10.1016/j.jtcvs.2018.09.010
}

In this issue of the Journal, Matalanis and $\mathrm{Ip}^{1}$ report their management paradigm for total aortic repair for the treatment of acute type A dissection (ATAD). Matalanis and $\mathrm{Ip}^{1}$ advocate a total arch repair for "the majority" of patients with ATAD. Those with evolving malperfusion, rapidly enlarging false lumen, or collapsed true lumen would proceed to stenting of the entire thoracoabdominal aorta, with a proximal covered stent, distal bare metal stents, and balloon rupture of the septum. Of the 72 patients who underwent surgery for ATAD in the report of Matalanis and Ip, 12 patients $(16.7 \%)$ underwent total aortic repair with the described technique in the acute setting; an additional 3 patients had endovascular completion in the chronic phase. The results reported are outstanding, with no early deaths and a low rate of neurologic and other complications.

Matalanis and his group are to be commended for developing an intriguing approach to ATAD that should reduce the need for late aortic intervention. They have described this approach in several papers, ${ }^{2-8}$ however, many pertinent details remain missing. Of particular interest are the following unanswered questions: (1) What were the clinical features, initial management, technical details, and outcomes of all patients presenting with ATAD? (2) Which patients received total arch (as opposed to hemiarch) repair, and what were the outcomes for the index arch operation? (3) Which patients had an indication develop for distal aortic intervention? (4) How did the radiologic features of the dissection evolve during follow-up?

Some technical aspects deserve commentary. We contend that the general cardiac surgeon with limited aortic experience should perform the standard operation and save the patient's life. ${ }^{9}$ Many have advocated more extensive repairs, including total aortic repair from the valve to the bifurcation, initially described 30 years ago. ${ }^{10}$ For those who require extended repair, a total arch repair with a frozen elephant trunk would have the additional advantages of

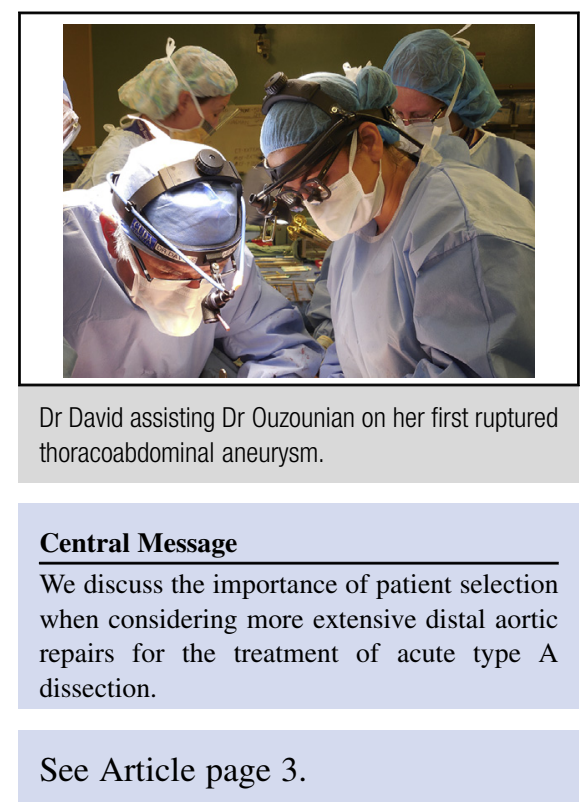

covering any primary or large reentry tears in the proximal descending thoracic aorta, improving hemostasis by depressurizing the false lumen at the distal anastomotic site, and reexpanding the collapsed distal true lumen to alleviate any distal malperfusion. ${ }^{11-13}$ Although one could then add bare metal stents down to the abdominal aorta, only a small minority of patients treated with a frozen elephant trunk will need reintervention. Furthermore, we find that the frozen elephant trunk provides the ideal platform for subsequent endovascular interventions by providing a longer, straight segment landing zone that does not require traversing the arch. Anatomic reimplantation of the arch vessels facilitates cannulation visceral branches from above more readily than does a trifurcated arch graft that has been implanted (by necessity) close to the sinotubular junction.

We suspect that in carefully selected case, a more extensive primary operation for ATAD performed by an aortic specialist that facilitates subsequent distal interventions would be ideal. We look forward to a detailed report with late imaging and clinical outcomes of all patients with ATAD managed at the unit of Matalanis and Ip. ${ }^{1}$ Only then will we be better positioned to understand which patients may benefit from this aggressive strategy. For the surgeon practicing today, we advise this: know your patient and know yourself. 


\section{References}

1. Matalanis G, Ip S. A new paradigm in the management of acute type A aortic dissection: total aortic repair. J Thorac Cardiovasc Surg. 2019;157:3-11.

2. Matalanis G, Ip S. Total aortic repair for acute type A aortic dissection: a new paradigm. J Vis Surg. 2018;4:79.

3. Galvin SD, Perera NK, Matalanis G. Technical aspects of total aortic repair in the surgical management of acute type A aortic dissection. Ann Cardiothorac Surg. 2016;5:248-50.

4. Galvin SD, Perera NK, Matalanis G. Surgical management of acute type A aortic dissection: branch-first arch replacement with total aortic repair. Ann Cardiothorac Surg. 2016;5:236-44.

5. Matalanis G, Perera NK, Galvin SD. Total aortic repair: the new paradigm in the treatment of acute type A aortic dissection. Ann Cardiothorac Surg. 2016;5: 216-21.

6. Perera NK, Galvin SD, Brooks M, Seevanayagam S, Matalanis G. Total aortic repair for acute type A aortic dissection complicated by malperfusion or symptomatic branch vessel malalignment. Ann Thorac Surg. 2016;101:2398-400.

7. Galvin SD, Matalanis G. Continuous perfusion "Branch-first" aortic arch replacement: a technical perspective. Ann Cardiothorac Surg. 2013;2:229-34.

8. Matalanis G, Galvin SD. "Branch-first" continuous perfusion aortic arch replacement and its role in intra-operative cerebral protection. Ann Cardiothorac Surg. 2013;2:194-201.

9. David TE. Surgery for acute type A aortic dissection. J Thorac Cardiovasc Surg. 2015;150:279-83.

10. Massimo CG, Presenti LF, Marranci P, Favi PP, Poma AG, Ponzalli M, et al. Extended and total aortic resection in the surgical treatment of acute type A aortic dissection: experience with 54 patients. Ann Thorac Surg. $1988 ; 46: 420-4$

11. Smith HN, Boodhwani M, Ouzounian M, Saczkowski R, Gregory AJ, Herget EJ, et al. Classification and outcomes of extended arch repair for acute type A aortic dissection: a systematic review and meta-analysis. Interact Cardiovasc Thorac Surg. 2017;24:450-9.

12. Shrestha M, Haverich A, Martens A. Total aortic arch replacement with the frozen elephant trunk procedure in acute DeBakey type I aortic dissections. Eur J Cardiothorac Surg. 2017;51(Suppl 1):i29-34.

13. Takagi H, Umemoto T, ALICE Group. A meta-analysis of total arch replacement with frozen elephant trunk in acute type A aortic dissection. Vasc Endovascular Surg. 2016;50:33-46. 